\title{
Water, sanitation and hygiene interventions for acute childhood diarrhea: a systematic review to provide estimates for the Lives Saved Tool
}

Nazia Darvesh', Jai K. Das², Tyler Vaivada', Michelle F. Gaffey ${ }^{1}$, Kumanan Rasanathan ${ }^{3}$ Zulfiqar A. Bhutta ${ }^{1,4^{*}}$ and for the Social Determinants of Health Study Team

\begin{abstract}
Background: In the Sustainable Development Goals (SDGs) era, there is growing recognition of the responsibilities of non-health sectors in improving the health of children. Interventions to improve access to clean water, sanitation facilities, and hygiene behaviours (WASH) represent key opportunities to improve child health and well-being by preventing the spread of infectious diseases and improving nutritional status.

Methods: We conducted a systematic review of studies evaluating the effects of WASH interventions on childhood diarrhea in children 0-5 years old. Searches were run up to September 2016. We screened the titles and abstracts of retrieved articles, followed by screening of the full-text reports of relevant studies. We abstracted study characteristics and quantitative data, and assessed study quality. Meta-analyses were performed for similar intervention and outcome pairs.

Results: Pooled analyses showed diarrhea risk reductions from the following interventions: point-of-use water filtration (pooled risk ratio (RR): 0.47, 95\% confidence interval (CI): 0.36-0.62), point-of-use water disinfection (pooled RR: 0.69, 95\% Cl: 0.60-0.79), and hygiene education with soap provision (pooled RR: $0.73,95 \%$ Cl: 0.57-0.94). Quality ratings were low or very low for most studies, and heterogeneity was high in pooled analyses. Improvements to the water supply and water disinfection at source did not show significant effects on diarrhea risk, nor did the one eligible study examining the effect of latrine construction.

Conclusions: Various WASH interventions show diarrhea risk reductions between 27\% and 53\% in children 0-5 years old, depending on intervention type, providing ample evidence to support the scale-up of WASH in low and middle-income countries (LMICs). Due to the overall low quality of the evidence and high heterogeneity, further research is required to accurately estimate the magnitude of the effects of these interventions in different contexts.
\end{abstract}

Keywords: Lives saved tool, LiST, Water, Sanitation, Hygiene, Wash, Diarrhea

\footnotetext{
*Correspondence: zulfiqar.bhutta@sickkids.ca

${ }^{1}$ Centre for Global Child Health, The Hospital for Sick Children, 686 Bay

Street, Toronto, ON M6S 156, Canada

${ }^{4}$ Centre of Excellence in Women and Child Health, Aga Khan University,

Karachi, Pakistan

Full list of author information is available at the end of the article
}

(c) The Author(s). 2017 Open Access This article is distributed under the terms of the Creative Commons Attribution 4.0 International License (http://creativecommons.org/licenses/by/4.0/), which permits unrestricted use, distribution, and reproduction in any medium, provided you give appropriate credit to the original author(s) and the source, provide a link to the Creative Commons license, and indicate if changes were made. The Creative Commons Public Domain Dedication waiver (http://creativecommons.org/publicdomain/zero/1.0/) applies to the data made available in this article, unless otherwise stated. 


\section{Background}

Clean water, availability of toilets and good hygiene practices are essential for the survival and development of children. Globally, there are 2.4 billion people who live without adequate sanitation, 663 million do not have access to improved water sources and 946 million still defecate in the open [1]. While there has been progress, it has been slow and uneven, with $96 \%$ of the global urban population using improved drinking water sources in 2015 compared to $84 \%$ of the rural population; $82 \%$ of the global urban population uses improved sanitation facilities compared to $51 \%$ of the rural population [1].

Children under the age of five years are the most affected as they are prone to water-borne diseases, especially diarrhea. It is estimated that over 800,000 children die annually from preventable diseases caused by poor water, lack of sanitation and poor hygiene [2]. Diarrhea is one of the leading causes of morbidity and mortality in children, and while there has been progress in the reduction of diarrhea-associated mortality [3], the reduction in incidence and morbidity has varied in different regions and between socio-economic classes. In particular, the relationship of early exposure to pathogens, diarrheal burdens, and high rates of stunting, also called environmental enteropathy, is well appreciated [4]. Poor status of water, sanitation and hygiene (WASH) and related interventions can impact growth and development of children in multiple ways [4] and there is consensus that improvement in undernutrition would not be possible without improving WASH conditions of underprivileged children around the world.

There are several interventions for improving WASH that have been implemented in varying contexts worldwide, with the evidence evaluated for their impact on health and social outcomes. The evidence so far has been sparse, complex, and not of sufficient quality to propose any conclusive impact of these interventions on broader health and other outcomes. Some of these difficulties relate to endpoints such as environmental enteropathy or developmental outcomes, and in other instances studies are not sufficiently powered to assess mortality outcomes. Diarrhea is a relevant outcome that has been evaluated relatively rigorously and has been used extensively in previous reviews to evaluate the effectiveness of WASH interventions in childhood [3-10]. We aimed to update the evidence synthesis presented by Cairncross et al. [7] which has guided interventions for the existing Lives Saved Tool (LiST) since 2010, and to propose fresh estimates for modeling within LiST.

\section{Methods}

\section{Search and data abstraction}

We systematically reviewed the published literature up to September 2016. We relied on a search that was previously conducted by our team for a broader evaluation of WASH interventions in September 2014 and updated that search in September 2016 to incorporate relevant new evidence. The search was conducted in Medline, CINAHL, EMBASE, CAB Abstracts, Cochrane, BLDS, EconLit, IDEAS, SIGLE, WHOLIS and JOLIS. Further articles from secondary sources were retrieved by screening the reference list of a Gapmap by Waddington and colleagues [11] and the reference lists of relevant reviews and reports [3-9]. A search strategy was designed including Medical Subject Heading Terms $(\mathrm{MeSH})$ and keywords using various combinations. No language or date restrictions were employed in the electronic searches.

We initially screened, in duplicate, the titles and abstracts of retrieved articles to determine whether they met our inclusion and exclusion criteria. The full-texts of all selected studies were then retrieved and assessed by two reviewers for eligibility. In duplicate, we abstracted descriptive and quantitative data from included studies into a standardized form.

\section{Inclusion/exclusion criteria}

Two authors independently assessed study eligibility using pre-defined inclusion and exclusion criteria. Discrepancies between the reviewers in the decision to include or exclude studies were resolved by discussion aimed at reaching consensus or by consulting with a third author.

We limited included studies to randomized controlled trials (RCTs), cluster randomized controlled trials (cRCTs) and quasi-experimental (QE) trials where the following WASH interventions were evaluated in community settings in children $0-5$ years old:

1. Water quality improvement at source and point-of-use

2. Promotion of handwashing with soap

3. Safe excreta disposal

We included studies published in English that evaluated the impact of these interventions on acute childhood diarrhea in children 0-5 years old. Our outcomes of interest included diarrhea-related mortality, diarrhea-related morbidity and risk of diarrhea. We excluded studies reporting only behavioral outcomes. We excluded studies comparing the effect of different interventions without a control group; studies conducted in specific settings such as schools, daycares, and hospitals; studies where the intervention was the use of hand scrubs or disinfectants; studies measuring the impact on dysentery only, specific pathogens such as cholera or soil-transmitted helminths (STHs), or general gastrointestinal outcomes like highlycredible gastrointestinal illness (HCGI); studies conducted in emergency settings or refugee camps; or studies conducted only with specific populations such as HIV- 
infected persons. We also excluded studies where multiple interventions were evaluated together and the impact of a single intervention could not be inferred, or where the data were not reported sufficiently to be included in a meta-analysis.

\section{Assessment of risk of bias}

The quality of studies was assessed using methods adapted from the Cochrane 'Risk of bias' assessment tool [12] and the Child Health Epidemiology Reference Group (CHERG) guidelines [13]. For each study, two reviewers independently assessed the quality of included studies for the following domains; allocation concealment, sequence generation; blinding of outcome assessors, blinding of participants and personnel, and incomplete outcome data. During quality assessment, RCTs and cRCTs started at a 'high' rating and quasi-experimental (QE) studies started at a 'low' rating with each study's rating adjusted accordingly and given either high, moderate, low or very low scores. Where a study reported multiple outcomes, we assigned a separate overall study score for each, depending on how the outcome was measured.

\section{Data analysis}

We entered the abstracted effect estimates into Review Manager (RevMan) 5.3 and made calculations where necessary $[12,14]$. In duplicate, the effect of the interventions on diarrheal outcomes was extracted, and calculated when necessary. These included risk ratios (RRs), odds ratios (ORs), rate ratios, means ratios, and longitudinal prevalence ratios, depending on how the individual study authors chose to display the effect. For treating all effect measures as equivalent, the design effect was considered for the various effect measures for common outcomes like diarrhea. The different measures of effect were then converted to a single measure for such outcomes [15]. In our analysis, ORs were transformed into RRs using an assumed control risk and formula recommended by Higgins et al. [12] .

Where studies presented outcomes at different time points, we selected the effect estimate from the longest follow-up time. When studies provided effect estimates separated into different age strata of children $0-5$ years old, we combined the point estimates from each stratum in RevMan using fixed effects models and then added the resulting pooled effect estimate into our main metaanalysis [16]. To quantitatively synthesize the available

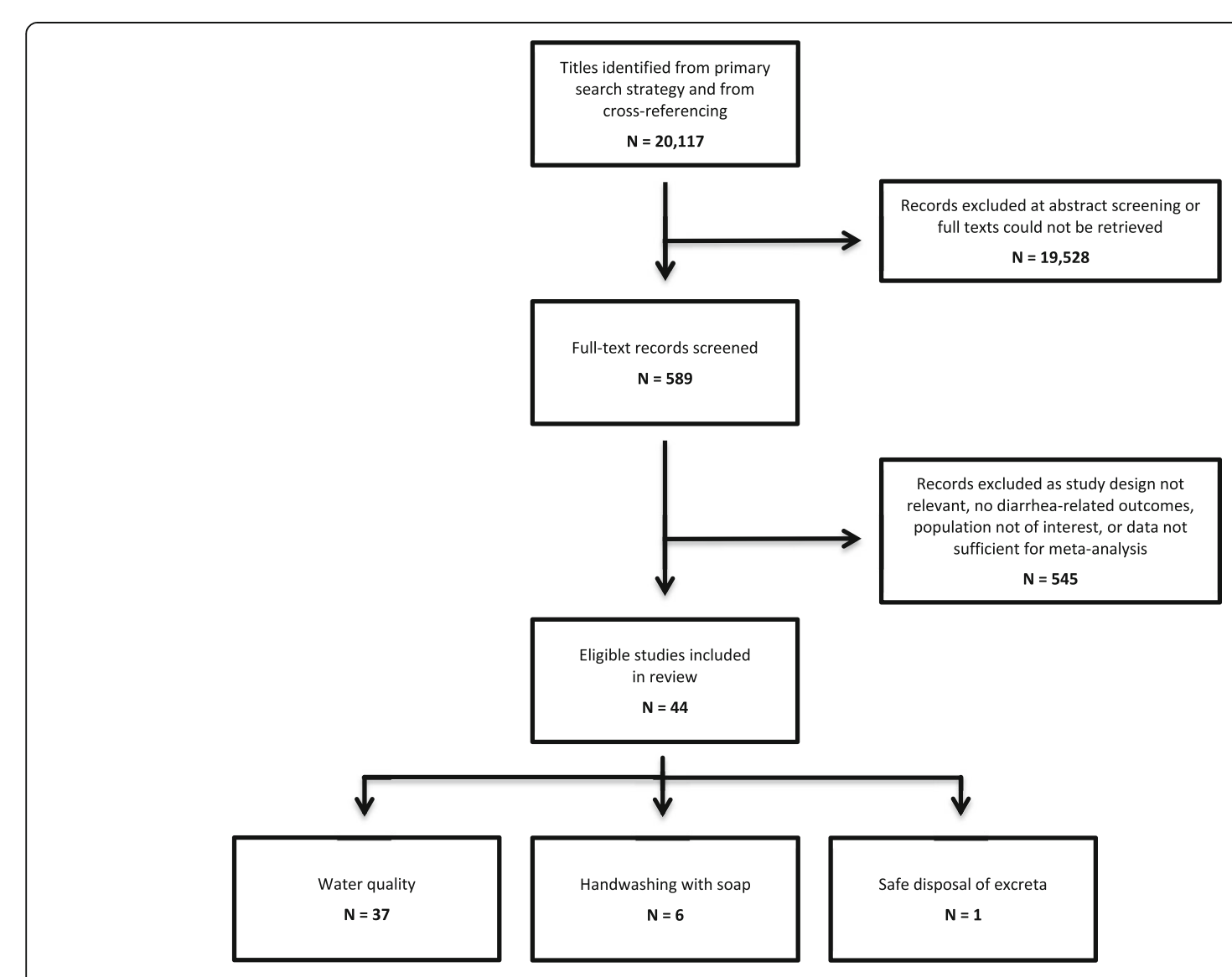

Fig. 1 Search flow diagram 
Table 1 Characteristics of included studies

\begin{tabular}{|c|c|c|c|c|}
\hline Study & Country & Study design & Intervention & $\begin{array}{l}\text { Estimates on diarrhea } \\
\text { (RR [95\% CI]) }\end{array}$ \\
\hline \multicolumn{5}{|c|}{ Improved water quality at source } \\
\hline Alam 1989 [17] & Bangladesh & QE & Hand Pump & $0.83[0.71,0.97]$ \\
\hline Opryszko 2010 [18] & Afghanistan & $\mathrm{CRCT}$ & Hand Pump & $1.22[0.86,1.73]$ \\
\hline Jensen 2003 [19] & Pakistan & QE & Chlorination & $0.95[0.35,2.60]$ \\
\hline Ryder 1985 [20] & Panama & QE & Improved Supply & $1.34[1.11,1.62]$ \\
\hline Semenza 1998 [21] & Uzbekistan & CRCT & Improved Supply & $0.65[0.44,0.95]$ \\
\hline \multicolumn{5}{|c|}{ Improved water quality at point-of-use } \\
\hline \multicolumn{5}{|l|}{ Water Filtration } \\
\hline Aceituno 2012 [22] & Honduras & $\mathrm{RCT}$ & Biosand Filter & $0.62[0.36,1.08]$ \\
\hline Boisson 2009 [23] & Ethiopia & $\mathrm{RCT}$ & Lifestraw & $0.97[0.67,1.40]$ \\
\hline Boisson 2010 [24] & Democratic Republic of Congo & $\mathrm{RCT}$ & Lifestraw & $0.85[0.56,1.29]$ \\
\hline Brown 2007 [25] & Cambodia & QE & Ceramic Filter & $0.52[0.32,0.85]$ \\
\hline \multirow[t]{2}{*}{ Brown 2008 [26] } & Cambodia & $\mathrm{RCT}$ & Ceramic Filter (Iron rich) & $0.58[0.41,0.82]$ \\
\hline & & & Ceramic Filter with Vessel & $0.65[0.46,0.92]$ \\
\hline Clasen 2004 [27] & Bolivia & $\mathrm{RCT}$ & Ceramic Filter & $0.41[0.17,1.02]$ \\
\hline Clasen 2005 [28] & Colombia & $\mathrm{RCT}$ & Ceramic Filter & $0.63[0.45,0.89]$ \\
\hline Du Preez 2008 [29] & South Africa and Zimbabwe & $\mathrm{RCT}$ & Ceramic Filter & $0.21[0.12,0.37]$ \\
\hline \multirow[t]{2}{*}{ Lindquist 2014 [30] } & Bolivia & $\mathrm{CRCT}$ & Hollow water filter & $0.21[0.15,0.29]$ \\
\hline & & & $\begin{array}{l}\text { Hollow water filter with } \\
\text { behavior change campaign }\end{array}$ & $0.27[0.22,0.33]$ \\
\hline Stauber 2009 [31] & Dominican Republic & $\mathrm{RCT}$ & Biosand Filter & $0.46[0.35,0.60]$ \\
\hline Stauber 2012a [32] & Ghana & $\mathrm{CRCT}$ & Biosand Filter & $0.26[0.07,0.97]$ \\
\hline Stauber 2012b [33] & Cambodia & $\mathrm{CRCT}$ & Biosand Filter & $0.45[0.26,0.78]$ \\
\hline Tiwari 2009 [34] & Kenya & $\mathrm{CRCT}$ & Biosand Filter & $0.49[0.24,1.00]$ \\
\hline \multicolumn{5}{|l|}{ Water Disinfection } \\
\hline Boisson 2013 [35] & India & $\mathrm{RCT}$ & Chlorination & $0.95[0.79,1.14]$ \\
\hline Chiller 2006 [36] & Republic of Guatemala & CRCT & Flocculent disinfectant & $0.63[0.48,0.82]$ \\
\hline \multirow[t]{2}{*}{ Crump 2005 [37] } & Kenya & $\mathrm{CRCT}$ & Flocculent disinfectant & $0.75[0.59,0.95]$ \\
\hline & & & Chlorination & $0.83[0.66,1.04]$ \\
\hline Du Preez 2011 [38] & Kenya & $\mathrm{RCT}$ & SODIS & $0.73[0.63,0.85]$ \\
\hline Harshfield 2012 [39] & Haiti & $\mathrm{QE}$ & Chlorination & $0.61[0.45,0.83]$ \\
\hline Jain 2010 [40] & Ghana & $\mathrm{RCT}$ & Chlorination & $1.13[0.92,1.39]$ \\
\hline Kirchhoff 1985 [41] & Brazil & QE & Chlorination & $0.97[0.84,1.12]$ \\
\hline \multirow[t]{2}{*}{ Luby 2006 (1) [42] } & Pakistan & $\mathrm{CRCT}$ & Chlorination & $0.39[0.17,0.89]$ \\
\hline & & & Flocculent disinfectant & $0.54[0.31,0.94]$ \\
\hline Mahfouz 1995 [43] & Saudi Arabia & QE & Chlorination & $0.55[0.30,1.00]$ \\
\hline McGuigan 2011 [44] & Cambodia & $\mathrm{CRCT}$ & SODIS & $0.37[0.29,0.47]$ \\
\hline Mengistie 2013 [45] & Ethiopia & $\mathrm{RCT}$ & Chlorination & $0.43[0.38,0.49]$ \\
\hline Mausezahl 2009 [46] & Bolivia & $\mathrm{CRCT}$ & SODIS & $0.74[0.50,1.10]$ \\
\hline Opryszko 2010 [18] & Afghanistan & $\mathrm{CRCT}$ & Chlorination & $1.20[0.84,1.71]$ \\
\hline Quick 1999 [47] & Bolivia & $\mathrm{CRCT}$ & Chlorination & $0.56[0.45,0.69]$ \\
\hline Rai 2010 [48] & India & $\mathrm{RCT}$ & SODIS & $0.24[0.10,0.60]$ \\
\hline \multirow[t]{2}{*}{ Reller 2003 (1) [49] } & Republic of Guatemala & $\mathrm{RCT}$ & Chlorination & $0.77[0.29,2.08]$ \\
\hline & & & Chlorination with vessel & $0.92[0.65,1.30]$ \\
\hline
\end{tabular}


Table 1 Characteristics of included studies (Continued)

\begin{tabular}{cllll}
\hline & & & Flocculent disinfectant & $0.69[0.50,0.95]$ \\
& & & Flocculent disinfectant with vessel & $1.05[0.78,1.41]$ \\
Rose 2006 [50] & India & QE & SODIS & $0.64[0.48,0.86]$ \\
Semenza 1998 [21] & Uzbekistan & CRCT & Chlorination & $0.33[0.19,0.57]$ \\
Sobsey 2003 [51] & Bangladesh & RCT & Chlorination & $0.78[0.73,0.83]$ \\
HANDWASHING WITH SOAP & & & & $0.70[0.54,0.93]$ \\
Han 1989 [52] & Myanmar & CRCT & With Provision of Soap & $0.74[0.54,1.01]$ \\
Langford 2011 [53] & Nepal & CRCT & With Provision of Soap & $0.55[0.45,0.68]$ \\
Luby 2004a [54] & Pakistan & CRCT & With Provision of Soap & $1.10[0.77,1.57]$ \\
Nicholson 2014 [55] & India & CRCT & With Provision of Soap & $0.53[0.44,0.62]$ \\
Shahid 1996 [56] & Bangladesh & QE & With Provision of Soap & $1.13[0.79,1.62]$ \\
Sircar 1987 [57] & India & QE & With Provision of Soap & \\
Safe disposal of excreta & & & & Latrine promotion and construction \\
Clasen 2014 [64] & India & CRCT & $0.97[0.83-1.12]$ \\
\hline
\end{tabular}

evidence, we grouped together similar intervention and outcome types and conducted meta-analyses using the generic inverse variance method. Random effects models were used to estimate the average effect of the intervention under the assumption that the intervention effects from individual studies were drawn from a distribution of effects rather than indicating the same fixed effect. For each intervention-outcome pair, the pooled RR was reported with a $95 \%$ confidence interval (CI). Subgroup analysis was conducted for the difference in the intervention.

\section{Quality of evidence}

After each study was assessed for methodological quality and assigned a rating according to the CHERG adaptation of the GRADE technique [13], the quality of the overall evidence for each intervention and outcome combination was assessed on a four-level scale (high, moderate, low, very low).

\section{Results}

Figure 1 shows the results of the search strategy and altogether a total of 44 studies were identified to be included in the review. The characteristics of included studies are described in Table 1 . The quality assessment of these studies suggests that the evidence is of low to very low quality (Table 2).

\section{Water quality improvement}

We identified five studies that provided water quality improvement intervention at the water supply [17-21]; two studies were cRCTs and three were QE. All of these studies were conducted in low and middle-income (LMIC) settings and the interventions included improved supply systems, hand pumps, and water disinfection (chlorination). The combined analysis suggested no effect of water quality interventions at source on risk of diarrhea (pooled RR: 0.98 95\%CI: 0.73, 1.32) and the subgroup analyses for the various interventions also suggested no effects (Fig. 2).

We identified 32 studies for inclusion in analysis that had a water quality improvement intervention at pointof-use [18, 21-51]; 27 of these were RCTs or cRCTs while five were QE study designs. Studies were from Africa (Kenya, Ghana, Democratic Republic of the Congo, Ethiopia, Zimbabwe, South Africa), Asia (Bangladesh, Pakistan, India, Afghanistan, Saudi Arabia, Uzbekistan, Cambodia), South America (Bolivia, Brazil, Colombia), Central America (Honduras, Guatemala), and the Caribbean (Haiti, Dominican Republic). There were a range of interventions delivered which were broadly categorized into 'water filtration' [22-34] and 'water disinfection' $[18,21,35-51]$ interventions. Water filtration interventions included biosand filters, ceramic filters, lifestraws, and hollow water filters while disinfection interventions included chlorination, use of flocculent-disinfectant, and solar disinfection (SODIS). One study reported the impact of flocculent-disinfectant on all-cause mortality in children under the age of two years and reported a $65 \%$ reduction (RR: 0.35, 95\%CI: 0.13, 0.94) [37]. Overall, 'water quality interventions at the point-of-use' showed a significant decrease in risk of diarrhea by $40 \%$ (RR: 0.60 , 95\%CI: $0.53,0.68)$, while the subgroup analyses suggested a $53 \%$ decrease (pooled RR: 0.47, 95\% CI: 0.36, 0.62 ) with respect to water filtration and a $31 \%$ decrease (pooled RR: 0.69, 95\% CI: 0.60, 0.79) with respect to water disinfection (Fig. 3). A further subgroup analysis suggested a significant effect for each of the specific interventions except for lifestraw (Fig. 4). 
Table 2 Quality assessment of the evidence

\begin{tabular}{|c|c|c|c|c|c|}
\hline & Quality As & ssessment & & & \\
\hline $\begin{array}{l}\text { Number } \\
\text { of } \\
\text { studies }\end{array}$ & $\begin{array}{l}\text { Study } \\
\text { design(s) }\end{array}$ & Limitations & Consistency & Generalizability & Overall quality of evidence (justification) \\
\hline \multicolumn{6}{|c|}{ Effect Of Water Quality Interventions at Source } \\
\hline \multicolumn{6}{|c|}{ Outcome: Diarrhea incidence or prevalence } \\
\hline 5 & $\begin{array}{l}2 \mathrm{CRCT} \\
3 \mathrm{QE}\end{array}$ & $\begin{array}{l}3 \text { very low, } \\
1 \text { low, } 1 \\
\text { moderate } \\
\text { quality study }\end{array}$ & $\begin{array}{l}\mathrm{I}^{2}=81 \% \\
\text { Studies favoured } \\
\text { intervention, } \\
\text { control, or } \\
\text { showed no effect }\end{array}$ & $\begin{array}{l}\text { Children 0-5 years; low and middle income } \\
\text { countries (Afghanistan, Bangladesh, Pakistan, } \\
\text { Panama, Uzbekistan) }\end{array}$ & $\begin{array}{l}\text { Very low } \\
\text { (considerable heterogeneity, non-significant } \\
\text { pooled estimate) }\end{array}$ \\
\hline
\end{tabular}

Point-Of-Use Water Treatment Interventions

Intervention: Water filters and water disinfection, Outcome: Diarrhea incidence or prevalence

$\begin{array}{llll}152 \mathrm{RCT}, & 17 \text { very low, } & \mathrm{I}^{2}=89 \% & \text { Children 0-5 years; low and middle } \\ 12 \mathrm{CRCT}, \quad 11 \text { low, } 4 & \text { Studies either } & \text { income countries } \\ 5 \mathrm{QE} & \begin{array}{l}\text { moderate } \\ \text { quality studies }\end{array} & \begin{array}{l}\text { (Afghanistan, Bangladesh, Bolivia, Brazil, } \\ \text { intervention or } \\ \text { showed no effect }\end{array} & \begin{array}{l}\text { Cambodia, Colombia, Democratic Republic } \\ \text { of Congo, Dominican Republic, Ethiopia, } \\ \text { Ghana, Guatemala, Haiti, India, Honduras, } \\ \text { Genya, Pakistan, Saudi Arabia [rural], South } \\ \end{array} \\ & & \text { Africa, Uzbekistan, Zimbabwe) }\end{array}$

Intervention: Water filters, Outcome: Diarrhea incidence or prevalence

$\begin{array}{llll}\text { 8 RCT, } & 8 \text { very low, } & \mathrm{I}^{2}=84 \% \\ 4 \mathrm{CRCT}, & 5 \text { low quality } & \text { Studies generally } \\ 1 \mathrm{QE} & \text { studies } & \text { favoured } \\ & \text { intervention }\end{array}$

Intervention: Water disinfection, Outcome: Diarrhea incidence or prevalence

$\begin{array}{lll}\text { 19 RCT, } & 9 \text { very low, } & 1^{2}=87 \% \\ 8 \mathrm{CRCT}, & 6 \text { low, } 4 & \text { Studies either } \\ 4 \mathrm{QE} & \begin{array}{l}\text { moderate } \\ \text { quality studies }\end{array} & \begin{array}{l}\text { favoured } \\ \text { intervention or } \\ \text { showed no effect }\end{array}\end{array}$
Children 0-5 years; low and middle income countries (Bolivia, Cambodia, Colombia, Democratic Republic of Congo, Dominican Republic, Ethiopia, Ghana, Honduras, Kenya, South Africa, Zimbabwe)

Children 0-5 years; low and middle income countries

(Afghanistan, Bangladesh, Bolivia, Brazil, Cambodia, India, Ethiopia, Ghana, Guatemala, Haiti, Kenya, Pakistan, Saudi Arabia [rural], Uzbekistan)

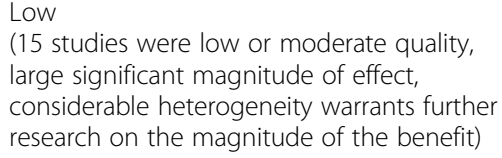

Very low

(mostly very low quality studies)

Hand Washing Education with Soap Interventions

Outcome: Diarrhea incidence or prevalence

$\begin{array}{lll}6 \quad \mathrm{CRCT}, & 5 \text { very low, } & \mathrm{I}^{2}=81 \% \\ & \text { 1 low quality } & \text { Studies either } \\ \text { study } & \text { favoured } \\ & \text { intervention or } \\ & \text { showed no effect }\end{array}$

Children 0-5 years; low and middle Very low income countries (Bangladesh, India, Myanmar, Nepal, Pakistan)
Low

(studies ranged from very low to moderate quality, large significant magnitude of effect, considerable heterogeneity warrants further research on the magnitude of the benefit)

\section{Handwashing with soap}

We identified six studies which evaluated the effect of handwashing with soap [52-57]; four were cRCTs and two were QE study designs. All studies were conducted in South Asian countries. Study participants were provided soap with education about handwashing before eating or food handling, after defecation or handling of child stools, or a combination of these. No study reported on mortality and the analysis suggests that handwashing with soap leads to a $27 \%$ decrease in risk of diarrhea (pooled RR: 0.73, 95\% CI: 0.57, 0.94) (Fig. 5).

\section{Excreta disposal}

The search for studies for excreta disposal interventions resulted in few studies with study designs that met our inclusion criteria, and some studies had other interventions including water supply interventions or multiple interventions evaluated together, hence the impact of excreta disposal alone could not be ascertained [58-63]. One study was included which showed that latrine construction in India increased mean village-level latrine coverage from $9 \%$ of households to $63 \%$ in the intervention group, but there was no impact on the risk of diarrhea in children younger than 5 years (RR: 0.97, 95\% CI: 0.83-1.12)[64].

\section{Discussion}

The review findings suggest that point-of-use water quality improvement interventions are effective in reducing the risk of diarrhea by $40 \%$ in children $0-5$ years 


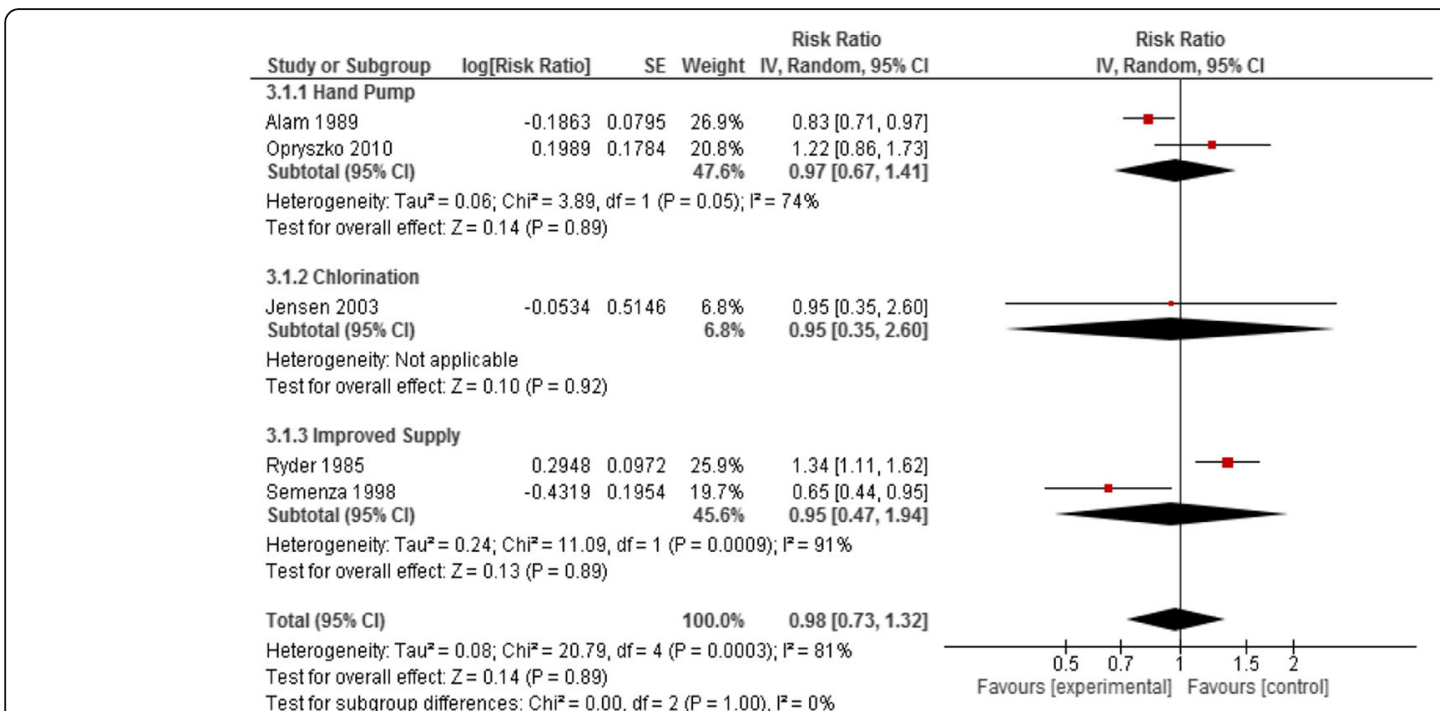

Fig. 2 Forest plot for the effect of water quality improvement at source on diarrhea

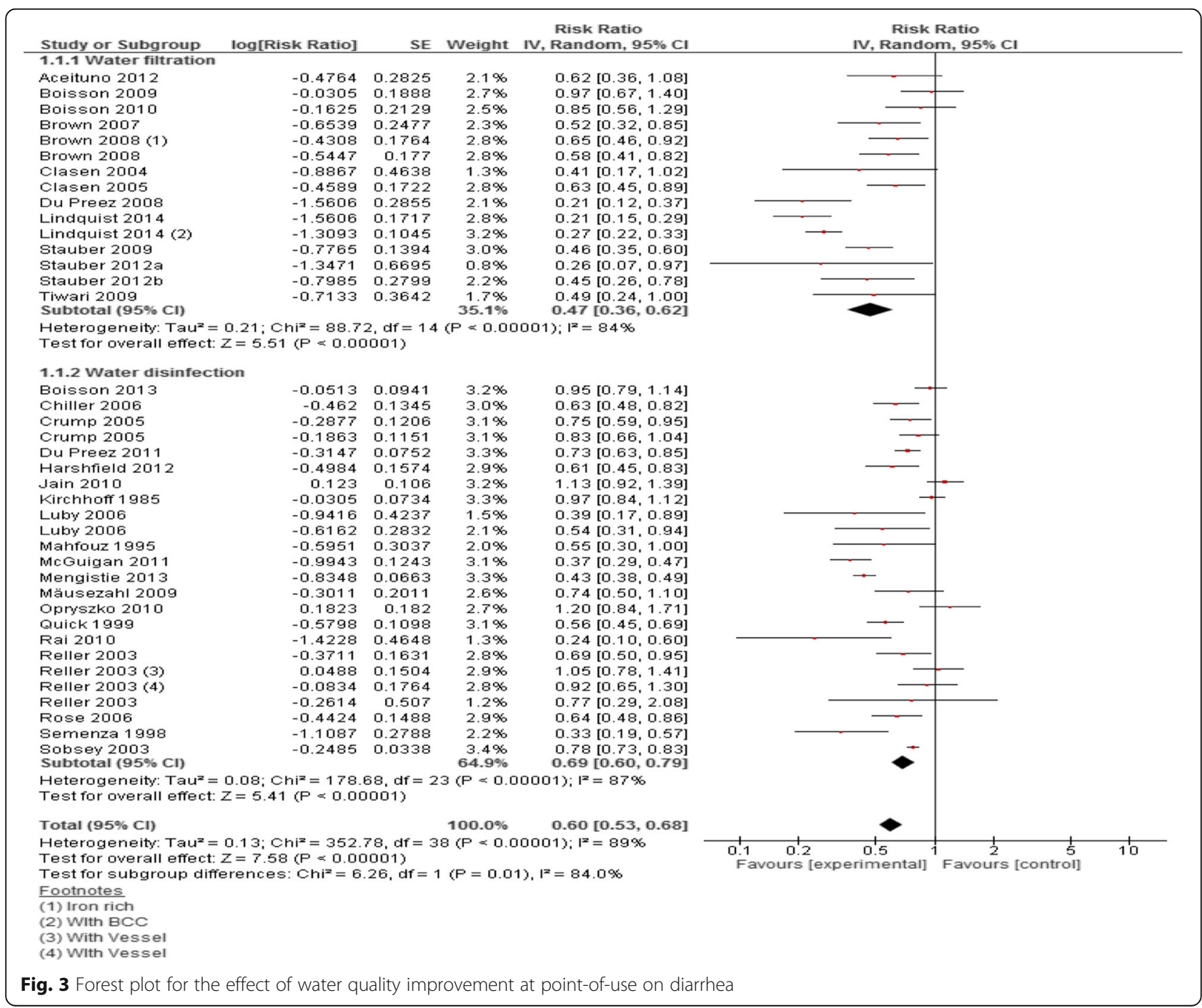




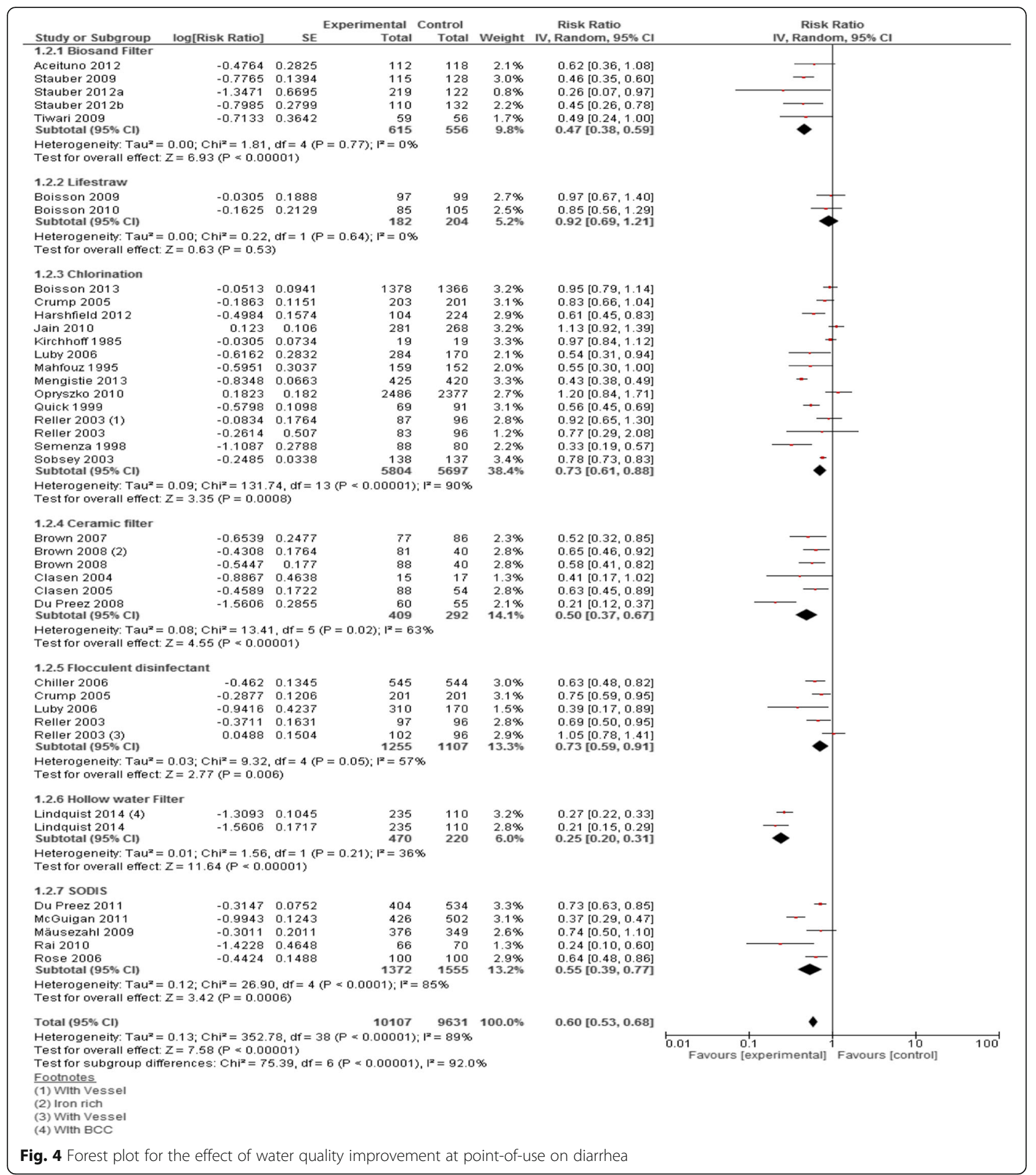

old in communities living in LMICs and subgroup analyses suggest greater impacts with water filtration (53\%) than with water disinfection (31\%). In addition, hand washing promotion with soap can lead to $27 \%$ reduction in risk of diarrhea. Evidence for the effect of water supply interventions at source and safe excreta of stools is insufficient to conclude an impact on childhood diarrhea. The overall quality of evidence is low to very low since most studies were not blinded - a design which may be difficult and unethical to adhere to in this context.

We did a de novo search for studies with specific inclusion and exclusion criteria which could provide precise estimates for inclusion in LiST, and also updated the evidence since the last LiST review which was published 


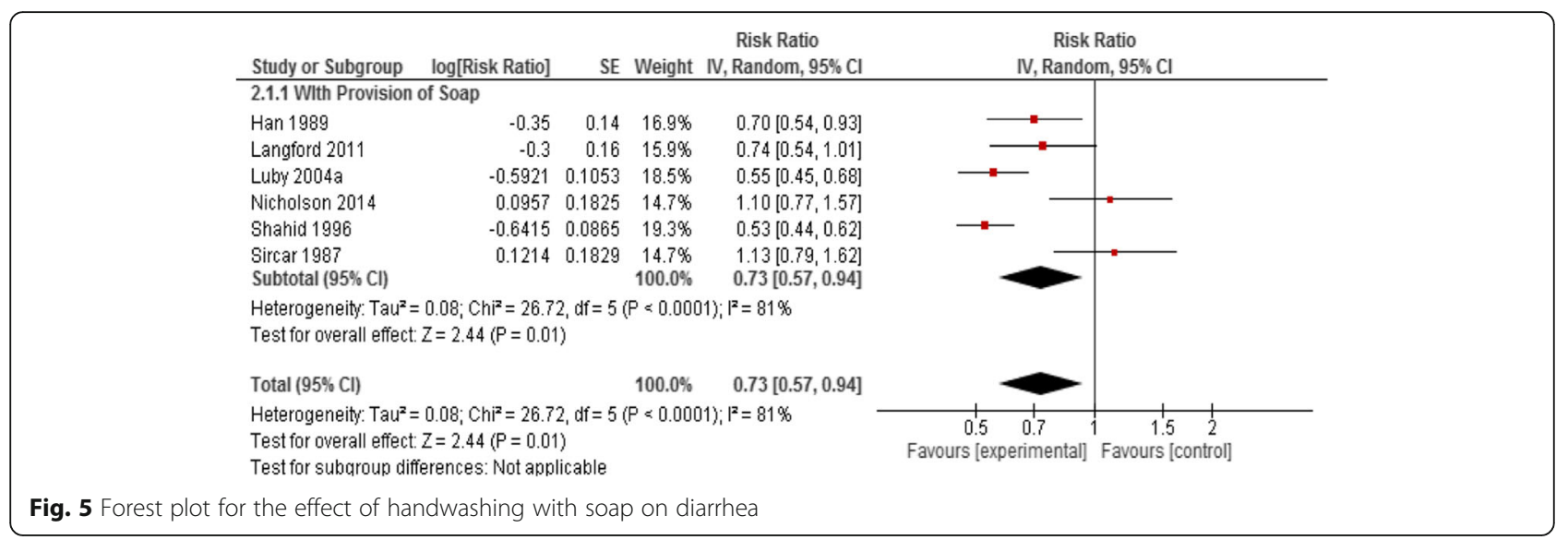

more than five years ago. As only one study for water quality improvement assessed all-cause mortality and the number of events were less than 50 [37], we propose our estimates based on diarrhea risk reductions $40 \%$ and $27 \%$ for point-of-use water quality interventions and handwashing with soap respectively. The evidence for water quality interventions at source and safe excreta disposal is too limited to propose an estimate for LiST.

Our results are broadly consistent with prior reviews in this area [3-10], though the estimated magnitudes of intervention effect are different than those proposed by Cairncross et al. [7], which were $17 \% \%$ and $48 \%$ for water quality interventions and handwashing with soap, respectively. In addition to the inclusion of more recent evidence in the present review, the differences between the present and previous LiST review may be attributable to choice of effect measure, study designs, populations and settings. The previous LiST review [7] included observational studies and evidence from settings other than those in LMIC communities, including studies conducted in schools, daycare centres, refugee camps, out-patient clinics, and hospitals, and it also included studies conducted in children over the age of five. The previous review also included studies with primary outcomes of typhoid, cholera or dysentery, while we only included studies reporting on diarrhea. We propose an estimate for water quality improvement at point-of-use only, as the evidence is more consistent, while there is limited evidence for water quality improvement at source and suggest a non-significant impact on diarrhea.

While point-of-use water quality interventions and handwashing promotion with soap appear to be effective in reducing diarrhea, much of the evidence is from trials conducted in small populations over short time periods. More evidence is needed on compliance over a longer duration to assess sustainability. The challenge is to find ways of encouraging people to maintain handwashing habits in the longer term. The need to conduct research with longer follow-up duration using a structured method of assessing the primary outcome is pertinent, since it has been observed that the choice of method may have significant effects on the precision of estimates. Outcome assessors should be blinded so as to reduce the bias in estimates of effect size. Self-reported outcome measurements such as diarrhea frequency are prone to recall and other biases, which contributed in part to the low methodological quality ratings overall. There are a number of large scale trials underway with results eagerly awaited which might shed further light on the short and long-term impact of WASH interventions at scale [65].

The importance of WASH strategies for reducing childhood diarrhea is fairly established, but the challenge remains to make their availability universal. Sustainable Development Goal (SDG) 6 covers the whole water cycle, and includes targets for universal access to drinking water, sanitation, and hygiene that are significantly more ambitious than the previous targets of the Millennium Development Goals (MDGs). To accomplish these goals, changing behaviours and social norms is essential, governance and accountability should be ensured, and inequalities will have to be eliminated.

\section{Abbreviations \\ CHERG: Child Health Epidemiology Reference Group; CRCT: cluster randomized controlled trials; GRADE: Grading of Recommendations Assessment, Development and Evaluation; LMIC: low and middle-income countries; QE: quasi-experimental; RCT: randomized controlled trials; SDG: Sustainable Development Goals; WASH: water, sanitation and hygiene}

\section{Acknowledgements}

Not applicable.

\section{Funding}

The publication costs for all supplement articles were funded by a grant from the Bill \& Melinda Gates Foundation (JHU Grant 115,621, Award Number OPP1084423 for the "Development and Use of the Lives Saved Tool (LiST)")." 


\section{Availability of data and materials}

Not applicable.

\section{About this supplement}

This article has been published as part of BMC Public Health Volume 17 Supplement 4, 2017: The Lives Saved Tool in 2017: Updates, Applications, and Future Directions. The full contents of the supplement are available online at https://bmcpublichealth.biomedcentral.com/articles/supplements/ volume-17-supplement-4

\section{Authors' contributions}

All authors contributed to the review. All authors reviewed and approved of the final manuscript

\section{Authors' information}

Social Determinants of Health Study Team.

Zulfiqar A Bhutta, Nazia Darvesh, Andreea Seusan, Jelena Savic, Nisso Nurova, Azim Rattansi, Daina Als, Tyler Vaivada, Michelle F Gaffey (SickKids Centre for Global Child Health); Sue Cavill, Kumananan Rasanathan (UNICEF); Jai K Das (AKU).

\section{Ethics approval and consent to participate}

Not applicable.

\section{Consent for publication}

Not applicable.

\section{Competing interests}

We do not have any financial or non-financial competing interests for this review.

\section{Publisher's Note}

Springer Nature remains neutral with regard to jurisdictional claims in published maps and institutional affiliations.

\section{Author details}

${ }^{1}$ Centre for Global Child Health, The Hospital for Sick Children, 686 Bay Street, Toronto, ON M6S 156, Canada. ${ }^{2}$ Division of Women and Child Health, Aga Khan University, Karachi, Pakistan. ${ }^{3}$ UNICEF, New York, NY, USA. ${ }^{4}$ Centre of Excellence in Women and Child Health, Aga Khan University, Karachi, Pakistan.

\section{Published: 7 November 2017}

\section{References}

1. UNICEF/WHO. Progress on sanitation and drinking water. Update and MDG Assessment. 2015 [cited 2017 Apr 25]. Available from: https:/www.unicef. org/publications/index_82419.html

2. Mills JE, Cumming O, editors. The impact of water, sanitation and hygiene on key health and social outcomes: Review of evidence. UNICEF [Internet]. 2016 Jun [cited 2017 Apr 25] Available from: https:/www.unicef.org/wash/ files/The_Impact_of_WASH_on_Key_Social_and_Health_Outcomes_Review_ of_Evidence.pdf.

3. Fewtrell L, Kaufmann RB, Kay D, Enanoria W, Haller L, Colford JM Jr. Water, sanitation, and hygiene interventions to reduce diarrhea in less developed countries: a systematic review and meta-analysis. Lancet Infect Dis. 2005:5(1):42-52.

4. Arnold BF, Colford JM. Treating water with cholorine at point-of-use to improve water quality and reduce child diarrhea in developing countries: a systematic review and meta-analysis. Am J Trop Med Hyg. 2007;76(2):354-64.

5. Waddington $H$, Snilstveit $B$, White $H$, Fewtrell L. Water, sanitation and hygiene interventions to combat childhood diarrhea in developing countries. New Delhi, India: 3ie; 2009 Aug [cited 2017 Apr 25] Available from: http://www.3ieimpact.org/evidence/systematic-reviews/details/23/

6. Wolf J, Prüss-Ustün A, Cumming O, Bartram J, Bonjour S, Cairncross S, et al. Assessing the impact of drinking water and sanitation on diarrheal disease in low- and middle income settings: systematic review and meta-regression. Tropical Med Int Health. 2014;19(8):928-42.

7. Cairncross S, Hunt C, Boisson S, Bostoen K, Curtis V, Fung ICH, et al. Water, sanitation and hygiene for the prevention of diarrhea. Int J Epidemiol. 2010; 39(Suppl 1):i193-205.
8. Clasen TF, Alexander KT, Sinclair D, Boisson S, Peletz R, Chang HH, et al. Interventions to improve water quality for preventing diarrhea. Cochrane Database Syst Rev. 2015, Issue 10. Art. No.: CD004794. DOl: https://doi.org/ 10.1002/14651858.CD004794.pub3.

9. Ejemot-Nwadiaro RI, Ehiri JE, Arikpo D, Meremikwu MM, Critchley JA. Hand washing promotion for preventing diarrhea. Cochrane Database Syst Rev. 2015, Issue 9. Art. No.: CD004265. DOl: https://doi.org/10.1002/14651858. CD004265.pub3.

10. Clasen TF, Bostoen K, Schmidt WP, Boisson S, Fung ICH, Jenkins MW, et al. Interventions to improve disposal of human excreta for preventing diarrhea. Cochrane Database Syst Rev. 2010, Issue 6. Art. No.: CD007180. DOI: https:// doi.org/10.1002/14651858.CD007180.pub2.

11. Water, Sanitation and Hygiene Evidence Gap Map. 2015 [cited 2017 Apr 25]. Available from: http://gapmaps.3ieimpact.org/evidence-maps/watersanitation-and-hygiene-evidence-gap-map.

12. Higgins JPT, Green S. Cochrane Handbook for Systematic Reviews of Interventions Version 5.3 .0 (updated October 2015). The Cochrane Collaboration. 2015 [cited 2017 Apr 25]. Available from: http://training. cochrane.org/handbook

13. Walker N, Fischer-Walker C, Bryce J, Bahl R, Cousens S. Effects CRGol: Standards for CHERG reviews of intervention effects on child survival. Int J Epidemiol. 2010;39(Suppl 1):i21-31.

14. Review Manager (RevMan) In., 5.3 edn: Copenhagen: The Nordic Cochrane Centre, The Cochrane Collaboration; 2014.

15. Zhang J, Yu KF. What's the relative risk? A method of correcting the odds ratio in cohort studies of common outcomes. JAMA. 1998;280(19):1690-1.

16. Borenstein M, Larry V.H, Julian PT H, Rothstein HR. Introduction to MetaAnalysis: John Wiley \& Sons, Ltd. 2009.

17. Alam N, Wojtyniak B, Henry FJ, Rahaman MM. Mothers' personal and domestic hygiene and diarrhea incidence in young children in rural Bangladesh. Int J Epidemiol. 1989;18(1):242-7.

18. Opryszko MC, Majeed SW, Hansen PM, Myers JA, Baba D, Thompson RE, Burnham $G$. Water and hygiene interventions to reduce diarrhea in rural Afghanistan: a randomized controlled study. J Water Health. 2010; 8(4):687-702.

19. Jensen PK, Ensink JHJ, Jayasinghe G, van der Hoek W, Cairncross S, Dalsgaard A. Effect of chlorination of drinking-water on water quality and childhood diarrhea in a village in Pakistan. J Health Popul Nutr. 2003;21(1):26-31.

20. Ryder RW, Reeves WC, Singh N, Hall CB, Kapikian AZ, Gomez B, et al. The childhood health effects of an improved water supply system on a remote Panamanian island. Am J Trop Med Hyg. 1985;34(5):921-4.

21. Semenza JC, Roberts L, Henderson A, Bogan J, Rubin CH. Water distribution system and diarrheal disease transmission: a case study in Uzbekistan. Am J Trop Med Hyg. 1998:59(6):941-6.

22. Fabiszewski de Aceituno AM, Stauber CE, Walters AR, Meza Sanchez RE, Sobsey MD. A randomized controlled trial of the plastic-housing BioSand filter and its impact on diarrheal disease in Copan. Honduras Am J Trop Med Hyg. 2012;86(6):913-21

23. Boisson S, Schmidt WP, Berhanu T, Gezahegn H, Clasen T. Randomized controlled trial in rural Ethiopia to assess a portable water treatment device. Environmental science \& technology. 2009:43(15):5934-9.

24. Boisson S, Kiyombo M, Sthreshley L, Tumba S, Makambo J, Clasen T. Field assessment of a novel household-based water filtration device: a randomised, placebo-controlled trial in the Democratic Republic of Congo. PLoS One. 2010:5(9):e12613.

25. Brown J, Sobsey M, Proum S. Improving Household Drinking Water Quality Use of Ceramic Water Filters in Cambodia. 2007 [cited 2017 Apr 25]. Available from: https://www.unicef.org/eapro/WSP_UNICEF_FN_CWP_Final.pdf.

26. Brown J, Sobsey MD, Loomis D. Local drinking water filters reduce diarrheal disease in Cambodia: a randomized, controlled trial of the ceramic water purifier. T Am J Trop Med Hyg. 2008;79(3):394-400.

27. Clasen TF, Brown J, Collin S, Suntura O, Cairncross S. Reducing diarrhea through the use of household-based ceramic water filters: a randomized, controlled trial in rural Bolivia. Am J Trop Med Hyg. 2004;70(6):651-7.

28. Clasen T, Garcia Parra G, Boisson S, Collin S. Household-based ceramic water filters for the prevention of diarrhea: a randomized, controlled trial of a pilot program in Colombia. Am J Trop Med Hyg. 2005;73(4):790-5.

29. Du Preez M, Conroy RM, Wright JA, Moyo S, Potgieter N, Gundry SW. Use of ceramic water filtration in the prevention of diarrheal disease: a randomized controlled trial in rural South Africa and Zimbabwe. Am J Trop Med Hyg. 2008;79(5):696-701. 
30. Lindquist ED, George CM, Perin J, Neiswender de Calani KJ, Norman WR, Davis TP, et al. A cluster randomized controlled trial to reduce childhood diarrhea using hollow fiber water filter and/or hygiene-sanitation educational interventions. Am J Trop Med Hyg. 2014;91(1):190-7.

31. Stauber CE, Ortiz GM, Loomis DP, Sobsey MD. A randomized controlled trial of the concrete biosand filter and its impact on diarrheal disease in Bonao, Dominican Republic. Am J Trop Med Hyg. 2009;80(2):286-93.

32. Stauber CE, Kominek B, Liang KR, Osman MK, Sobsey MD. Evaluation of the impact of the plastic BioSand filter on health and drinking water quality in rural tamale, Ghana. Int J Environ Res Public Health. 2012;9(11):3806-23.

33. Stauber CE, Printy ER, McCarty FA, Liang KR, Sobsey MD. Cluster randomized controlled trial of the plastic BioSand water filter in Cambodia. Environmental science \& technology. 2012;46(2):722-8.

34. Tiwari SS, Schmidt WP, Darby J, Kariuki ZG, Jenkins MW. Intermittent slow sand filtration for preventing diarrhea among children in Kenyan households using unimproved water sources: randomized controlled trial. Tropical Med Int Health. 2009;14(11):1374-82.

35. Boisson S, Stevenson M, Shapiro L, Kumar V, Singh LP, Ward D, et al. Effect of household-based drinking water chlorination on diarrhea among children under five in Orissa, India: a double-blind randomised placebocontrolled trial. PLoS Med. 2013;10(8):e1001497.

36. Chiller TM, Mendoza CE, Lopez MB, Alvarez M, Hoekstra RM, Keswick BH, et al. Reducing diarrhea in Guatemalan children: randomized controlled trial of flocculant-disinfectant for drinking-water. Bull World Health Organ. 2006; 84(1):28-35.

37. Crump JA, Otieno PO, Slutsker L, Keswick BH, Rosen DH, Hoekstra RM, et al. Household based treatment of drinking water with flocculant-disinfectant for preventing diarrhea in areas with turbid source water in rural western Kenya: cluster randomised controlled trial. BMJ (Clinical research ed). 2005: 331(7515):478

38. du Preez M, Conroy RM, Ligondo S, Hennessy J, Elmore-Meegan M, Soita A, et al. Randomized intervention study of solar disinfection of drinking water in the prevention of dysentery in Kenyan children aged under 5 years Environmental science \& technology. 2011;45(21):9315-23.

39. Harshfield E, Lantagne D, Turbes A, Null C. Evaluating the sustained health impact of household chlorination of drinking water in rural Haiti. Am J Trop Med Hyg. 2012;87(5):786-95.

40. Jain S, Sahanoon OK, Blanton E, Schmitz A, Wannemuehler KA, Hoekstra RM, et al. Sodium dichloroisocyanurate tablets for routine treatment of household drinking water in periurban Ghana: a randomized controlled trial. Am J Trop Med Hyg. 2010;82(1):16-22

41. Kirchhoff LV, McClelland KE, Do Carmo Pinho M, Araujo JG, de Sousa MA, Guerrant RL. Feasibility and efficacy of in-home water chlorination in rural North-eastern Brazil. J Hyg. 1985;94(2):173-80.

42. Luby SP, Agboatwalla M, Painter J, Altaf A, Billhimer W, Keswick B, et al. Combining drinking water treatment and hand washing for diarrhea prevention, a cluster randomised controlled trial. Tropical Med Int Health. 2006;11(4):479-89.

43. Mahfouz AA, Abdel-Moneim M, Al-Erian RA, al-Amari OM. Impact of chlorination of water in domestic storage tanks on childhood diarrhea: a community trial in the rural areas of Saudi Arabia. J Trop Med Hyg. 1995;98(2):126-30.

44. McGuigan KG, Samaiyar P, du Preez M, Conroy RM. High compliance randomized controlled field trial of solar disinfection of drinking water and its impact on childhood diarrhea in rural Cambodia. Environmental science \& technology. 2011;45(18):7862-7.

45. Mengistie B, Berhane $Y$, Worku A. Household water chlorination reduces incidence of diarrhea among under-five children in rural Ethiopia: a cluster randomized controlled trial. PLoS One. 2013;8(10):e77887.

46. Mausezahl D, Christen A, Pacheco GD, Tellez FA, Iriarte M, Zapata ME, et al. Solar drinking water disinfection (SODIS) to reduce childhood diarrhea in rural Bolivia: a cluster-randomized, controlled trial. PLoS Med. 2009;6(8):e1000125.

47. Quick RE, Venczel LV, Mintz ED, Soleto L, Aparicio J, Gironaz M, et al. Diarrhea prevention in Bolivia through point-of-use water treatment and safe storage: a promising new strategy. Epidemiol Infect. 1999;122(1):83-90.

48. Rai B, Pal R, Kar S, Tsering DC. Solar disinfection improves drinking wate quality to prevent diarrhea in under-five children in sikkim. India J Glob Infect Dis. 2010;2(3):221-5.

49. Reller ME, Mendoza CE, Lopez MB, Alvarez M, Hoekstra RM, Olson CA, et al. A randomized controlled trial of household-based flocculant-disinfectant drinking water treatment for diarrhea prevention in rural Guatemala. Am J Trop Med Hyg. 2003;69(4):411-9.
50. Rose A, Roy S, Abraham V, Holmgren G, George K, Balraj V, et al. Solar disinfection of water for diarrheal prevention in southern India. Arch Dis Child. 2006;91(2):139-41.

51. Sobsey MD, Handzel T, Venczel L. Chlorination and safe storage of household drinking water in developing countries to reduce waterborne disease. Water Sci Technol. 2003:47(3):221-8.

52. Aung Myo $H$, Thein $H$. Prevention of diarrhea and dysentery by hand washing. Trans R Soc Trop Med Hyg. 1989;83(1):128-31.

53. Langford R, Lunn P, Panter-Brick C. Hand-washing, subclinical infections, and growth: a longitudinal evaluation of an intervention in Nepali slums. Am J Hum Biol. 2011:23(5):621-9.

54. Luby SP, Agboatwalla M, Painter J, Altaf A, Billhimer WL, Hoekstra RM. Effect of intensive handwashing promotion on childhood diarrhea in high-risk communities in Pakistan: a randomized controlled trial. JAMA. 2004;291(21):2547-54.

55. Nicholson JA, Naeeni M, Hoptroff M, Matheson JR, Roberts AJ, Taylor D, et al. An investigation of the effects of a hand washing intervention on health outcomes and school absence using a randomised trial in Indian urban communities. Tropical Med Int Health. 2014;19(3):284-92.

56. Shahid NS, Greenough WB 3rd, Samadi AR, Huq MI, Rahman N. Hand washing with soap reduces diarrhea and spread of bacterial pathogens in a Bangladesh village. J Diarrhoeal Dis Res. 1996;14(2):85-9.

57. Sircar BK, Sengupta PG, Mondal SK, Gupta DN, Saha NC, Ghosh S, et al. Effect of handwashing on the incidence of diarrhea in a Calcutta slum. Jiarrhoeal Dis Res. 1987:5(2):112-4.

58. KMA, Hoque BA, Hasan KZ, Patwary MY, SRA H, Rahman MM, et al. Reduction in diarrheal diseases in children in rural Bangladesh by environmental and behavioural modifications. Trans R Soc Trop Med Hyg. 1990;84(3):433-8.

59. Garrett V, Ogutu P, Mabonga P, Ombeki S, Mwaki A, Aluoch G, et al. Diarrhea prevention in a high-risk rural Kenyan population through pointof-use chlorination, safe water storage, sanitation, and rainwater harvesting. Epidemiol Infect. 2008;136(11):1463-71.

60. Huttly SR, Blum D, Kirkwood BR, Emeh RN, Okeke N, Ajala M, et al. The Imo state (Nigeria) drinking water supply and sanitation project, 2: impact on dracunculiasis, diarrhea and nutritional status. Trans R Soc Trop Med Hyg. 1990;84(2):316-21

61. Hu X-R, Liu G, Liu S-P, Yan-Xin H, Zhang X-M, Fan YY, et al. [Field evaluation of the effect of diarrhea control of methanogenesis treatment of human and animal faeces and rubbish of cellulose nature in the rural areas of Xiang Cheng]. Henan Yu Fang Yi Xue Za Zhi [Henan Journal of Preventative Medicine]. 1988;1988:11-13.

62. Messou E, Sangare SV, Josseran R, Le Corre C, Guelain J. Effect of hygiene and water sanitation and oral rehydration on diarrhea and mortality of children children less than five years old in the south of Ivory Coast. Bull Soc Pathol Exot. 1997;90(1):44-7.

63. Rubenstein A, Boyle J, Odoroff CL, Kunitz SJ. Effect of improved sanitary facilities on infant diarrhea in a Hopi village. Public Health Rep. 1969; 84(12):1093-7

64. Clasen T, Boisson S, Routray P, Torondel B, Bell M, Cumming O, Ensink J, et al. Effectiveness of a rural sanitation programme on diarrhea, soiltransmitted helminth infection, and child malnutrition in Odisha, India: a cluster-randomised trial. Lancet Glob Health. 2014;2(11):e645-53.

65. The Sanitation Hygiene Infant Nutrition Efficacy (SHINE) Trial Team. The sanitation hygiene infant nutrition efficacy (SHINE) trial: rationle, design, and methods. Clin Infect Dis. 2015:61(Supp7):S685-702. 